\title{
Online Position Control Performance Improving Applying Incremental Fuzzy Logic Controller
}

\author{
Dirman Hanafi ${ }^{1,3, *}$, Mohamed Najib Ribuan ${ }^{1}$, Wan HamidahWan Abas $^{2}$, Hidayat ${ }^{3}$, Elmy \\ Johana $^{1}$, Herman Wahid $^{4}$, Rozaimi Ghazali ${ }^{5}$, Hisyam Abdul Rahman ${ }^{1}$ \\ ${ }^{1}$ Instrumentation and Sensing Technology (InSeT) Research Group, Faculty of Electrical and Electronic \\ Engineering, Universiti Tun Hussein Onn Malaysia, Batu Pahat, 86400, Johor, Malaysia. \\ ${ }^{2}$ Department of Electrical Engineering, Politeknik Kuala Terengganu, Terengganu, Malaysia \\ ${ }^{3}$ Department of Electrical Engineering, Universitas Bung Hatta, Indonesia \\ ${ }^{4}$ Process Tomography \& Instrumentation Research Group (PROTOM-i), Faculty of Electrical \\ Engineering, Universiti Teknologi Malaysia, Johor, Malaysia. \\ ${ }^{5}$ Faculty of Electrical Engineering, Universiti Teknikal Malaysia Melaka, Melaka, Malaysia.
}

\begin{abstract}
This paper presents the online control system application for improving the DC motor performance. DC motor widely used in industries and many appliances. For this aim fuzzy logic controller is applied. The type of fuzzy controller use is an incremental fuzzy logic controller (IFLC). The IFLC is developed by using MATLAB Simulink Software and implemented in online position control system applying RAPCON board as a platform. The experimental results produced the best gains of the IFLC are 1.785, 0.0056955 and 0.01 for error gain (GE), gain of change error (GCE) and gain of output $(\mathrm{GCU})$ respectively. Its produce smaller rise time, peak time, $0 \%$ overshoot and smaller settling time. Beside that the IFLC response also able to follow the set point. The controller response parameters values are also acceptable. It means that the IFLC suitable to be use for improving the position control system performance.
\end{abstract}

\section{Introduction}

DC motors widely used to improve performance, such as industry, home appliances, robot manipulators etc. because it has high reliability, flexibility and low cost. Most DC motor driver applications are in position control or in speed control systems [1].

Several controllers have been applied for position control system with DC motor as a driver such as Proportional Integral Derivative (PID) [1], Fuzzy Logic [2,3], Neural Network (NN) [4] and etc.

PID controller is commonly applied for controlling motor because of it has simple structure and comprehensive control algorithms [1,2]. Besides, it has been implemented in position control systems, but still suffer from poor performance due to non-linear parameters. The PID controller does not provide satisfactory results when the control parameters, loading conditions and motor itself change [5].

\footnotetext{
*Corresponding author: dirman@uthm.edu.my
} 
Neural network (NN) controller is another kind of controllers that also has been applied for motor control. In the $\mathrm{NN}$, there is abundant of architecture can be used to perform a variety types of functions. There are kind of neural network with high efficiency and strong function generalizing in terms of learning speed and simplicity of the structure. The NN need increasing the number input $\mathrm{NN}$ and add some delay to the input $\mathrm{NN}$ to improve the performance [4].

In this paper, the incremental fuzzy logic controller (IFLC) as an intelligent controller is applied. The IFLC does not need knowledge model of system, complex structure, learning process and etc. This controller work is based on the principle of human expert decision making in problem solving mechanism [2,3]. The Mamdani inference as a computational fuzzy inference type is used because its decision is more accurate.

\section{DC Motor Modelling Approach}

In armature control of separately excited DC motors, the voltage applied to the armature of the motor is adjusted without changing the voltage applied to the field. Figure 1 describes a separately excited DC motor equivalent model $[1,6]$.

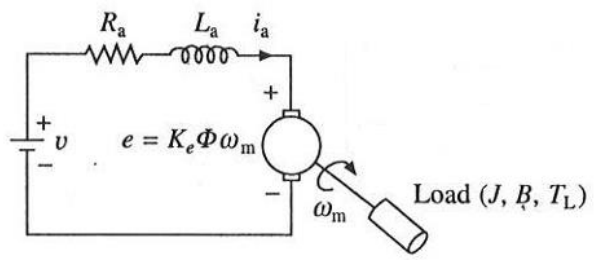

Fig.1.Separately excited DC motors

Where $\mathrm{J}$ is Moment of Inertia of the motor $\left(\mathrm{kg} \cdot \mathrm{m}^{2}\right)$, B is Friction coefficient of the motor(N.m.sec), $K_{e}$ is Torque constant of the motor (N.m/A), $\mathrm{K}_{\mathrm{b}}$ is Motor back emf constant $(\mathrm{V} / \mathrm{rad} / \mathrm{sec}), I_{a}$ is Armature current $(\mathrm{A}), V_{a}$ is Armature voltage applied (V), $\mathrm{R}_{\mathrm{a}}$ is Armature resistance (ohms), and $\mathrm{L}_{\mathrm{a}}$ is Armature inductance $(\mathrm{H})$.

\subsection{Dynamic Model}

Voltage equation of the armature circuit under transient is given by [6]

$$
v(t)=R_{a} i_{a}(t)+L_{a} \frac{d i_{a}(t)}{d t}+K_{e} \Phi \omega_{m}(t)
$$

From the dynamics of motor load system

$$
J \frac{d \omega_{m}(t)}{d t}=T(t)-T_{L}(t)-B \omega_{m}(t)
$$

Further

$$
T=K_{e} \Phi i_{a}(t)
$$

When field current is kept constant, flux remains constant. Replacing $K_{e} \phi$ by a constant $K_{e}$, yields

$$
\begin{aligned}
& v(t)=R_{a} i_{a}(t)+L_{a} \frac{d i_{a}(t)}{d t}+K_{e} \omega_{m}(t) \\
& J \frac{d \omega_{m}(t)}{d t}=K_{b} i_{a}(t)-B \omega_{m}(t)-T_{L}(t)
\end{aligned}
$$




$$
K_{b} i_{a}(t)=J \frac{d \omega_{m}(t)}{d t}+B \omega_{m}(t)-T_{L}(t)
$$

For no load previous equation become:

$$
K_{b} i_{a}(t)=J \frac{d \omega_{m}(t)}{d t}+B \omega_{m}(t)
$$

\subsection{Transfer Function}

Based on Laplace transforms of Eq. (1) and Eq. (6), the armatur current of motor is

$$
I_{a}(s)=\frac{\omega(s)}{K_{b}}\left[J_{m} s+B\right]
$$

Substitute Eq. (8) into Laplace form of Eq. (1) we get

$$
V(s)=\frac{\omega(s)}{K_{b}}\left[L_{a} J_{m} s^{2}+\left(L_{a} J_{m}+L_{a} B\right) s+\left(R_{a} B+K_{b} K_{e}\right)\right]
$$

The relation between position and speed are $\theta(s)=\frac{1}{s} \omega(s)$, then the transfers function between shaft position and armature voltage without load are given as:

$$
\frac{\theta(S)}{V(S)}=\frac{K_{b}}{L_{a} J_{m} s^{3}+\left(L_{a} J_{m}+L_{a} B\right) s^{2}+\left(R_{a} B+K_{b} K_{e}\right) s}
$$

\section{Incremental Fuzzy Control (IFLC)}

An IFLC [3] adds a change in control signal $\Delta u$ to the current control signal,

$$
u(n)=u(n-1)+\Delta u(n) T_{s} \Rightarrow \Delta u(n)=K_{p}\left(\frac{e(n)-e(n-1)}{T_{s}}+\frac{1}{T_{s}} e(n)\right)
$$

In Eq.(11) $T_{d}$ is 0 . For complete gain of PID, $\Delta u(n)$ become as below

$$
\Delta u(n)=K_{p}\left(e(n)+\frac{1}{T_{i}} \sum_{j=1}^{n} e(j) T_{s}+T_{d} \frac{e(n)-e(n-1)}{T_{s}}\right)(12
$$

Index $n$ refers to the time instant. By tuning we shall mean the activity of adjusting the parameters $K_{p}, T_{i}$, and $T_{d}$ in order to achieve a good closed-loop performance.

The IFLC as in Figure 2 is of almost the same configuration as the FPD controller except for the added integrator. The conclusion in the rule base is now called change in output $(C U)$, and the gain on the output is accordingly $G C U$. The control signal $U(n)$ at time instant $n$ is the sum of all previous increments,

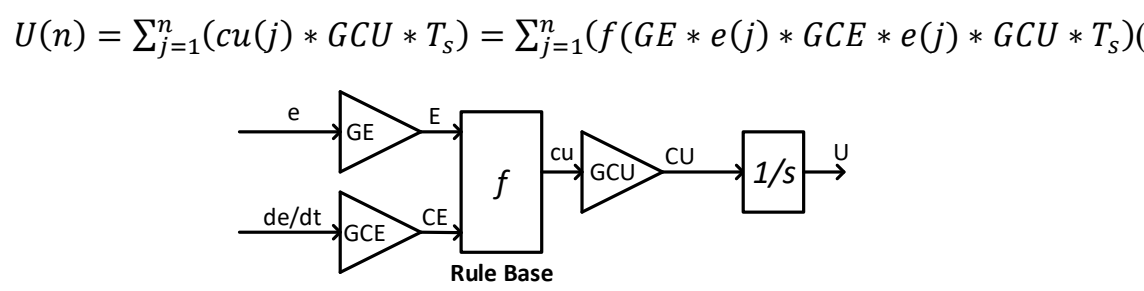

Fig.2. Incremental Fuzzy Logic Controller

Notice again that this definition deviates from the historical fuzzy controllers, where the sampling period $T_{s}$ was left out. The function $f$ is again the control surface of a PD rule base. 
The mapping is usually nonlinear, but with the usual favorable choice of design is a linear approximation as Eq.(14).

$$
f(G E * e(n), G C E * \dot{e}(n)) \approx G E * e(n)+G C E * \dot{e}(n)
$$

Insertion Eq. (14) into Eq.(13) yields the control action,

$$
\begin{array}{r}
U(n) \approx \sum_{j=1}^{n}(G E * e(j)+G C E * \dot{e}(j)) * G C U * T_{s}=G C U * \sum_{j=1}^{n}[G E * e(j)+G C E * \\
\left.\frac{e(j)-e(j-1)}{T_{S}}\right] * T_{S}=G C U\left[G E * \sum_{j=1}^{n} e(j) * T_{s}+G C E * \sum_{j=1}^{n}(e(j)-e(j-1))\right]=G C U * \\
G C E\left[\frac{G E}{G C E} \sum_{j=1}^{n}\left(e(j) * T_{s}\right)+e(n)\right](15)
\end{array}
$$

By assuming that $G C E * G C U=K_{p}, \frac{G E}{G C E}=\frac{1}{T_{i}}$ and $T_{d}=0$, it is clear that the linear controller is a crisp PI controller.

Note that the proportional gain $K_{p}$ now depends on $G C E$. The gain $1 / T_{i}$ was determined by the ratio between the two fuzzy input gains, and the inverse of the derivative gain $T_{d}$ in FPD control; the gains GE and GCE change roles in FPD and IFLC controllers.

\section{Online Position Control Implementation}

The online position control system with a DC motor as an actuator is implemented using computer, RAPCON board [7] and DC motor. Figure 3 (a) shows the hardware connection and (b) the IFLC controller block diagram.

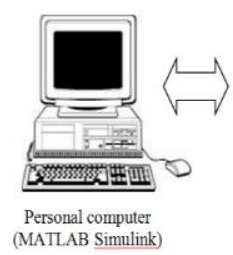

(MATLAB Simulink)

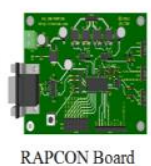

(a)

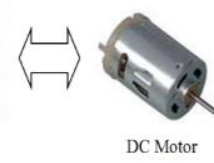

DC Motor

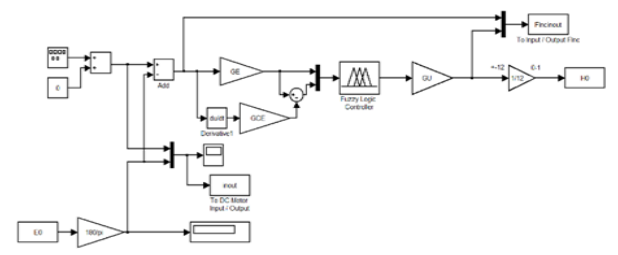

(b)

Fig.3.(a) Hardware components connection, (b) the IFLC controller block diagram

\section{Experimental Result and Analysis}

The experiment for testing the controller performance is done in two ways. There are simulation and online scheme.

\subsection{Simulation Scheme}

The best settings of controller parameters values for simulation scheme are 2.721, 0.019 and0.259 for GE, GCE and GCU respectively. Figure 4 (a) represents the output response of IFLC controller and (b) its zooming. 


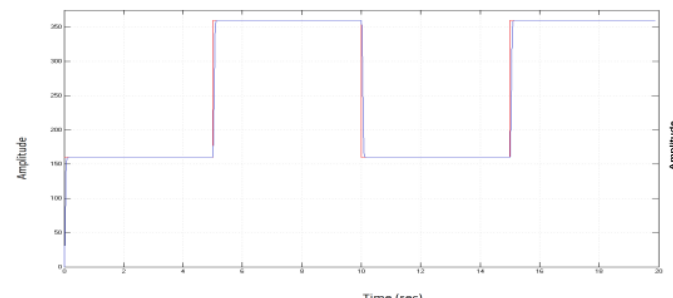

(a)

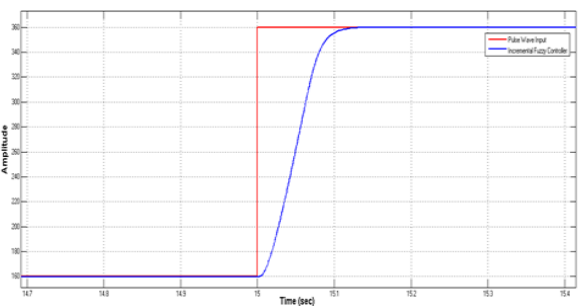

(b)

Fig.4.(a) Output response of IFLC controller, (b) its zooming.

\subsection{Online Scheme}

The best controller parameter values for online are 1.785, 0.0056955 and 0.01 for GE, GCE and GCU setting respectively.Reference inputs in this case combination between Signal Generator and Constant value. Figure 5 (a) represents the output response of IFLC for online scheme experiment and (b) its zooming.
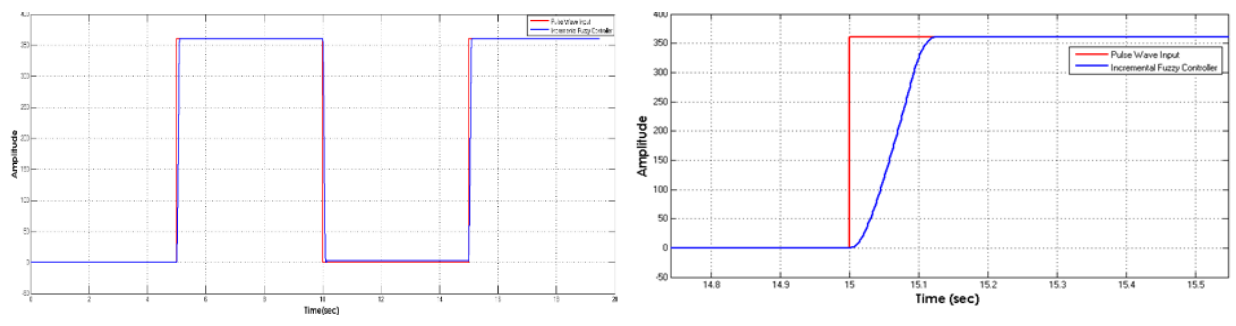

Fig.5.(a) Online IFLC response and(b) its zooming.

The IFLC responses specifications comparison between simulation and online are elaborated in Table 1.

Table 1. Specifications of IFLC response parameter

\begin{tabular}{|l|l|l|}
\hline Parameter & Simulation & Experiment \\
\hline Rise time, $T_{r}$ & $0.06 \mathrm{~s}$ & $0.085 \mathrm{~s}$ \\
\hline Peak time, $T_{p}$ & $0.12 \mathrm{~s}$ & $0.12 \mathrm{~s}$ \\
\hline Percent overshoot, \%OS & $0 \%$ & $0 \%$ \\
\hline Settling time, $T_{s}$ & $0.12 \mathrm{~s}$ & $0.12 \mathrm{~s}$ \\
\hline
\end{tabular}

\section{Conclusion}

Based on the experimental results show that the IFLC is a suitable control for improving the position control system performance. Its produce smaller rise time, peak time, $0 \%$ overshoot and smaller settling time. Beside that the IFLC response also able to follow the set point. This research was funded by Research Management Center (RMC) of Universiti Tun Hussein Onn Malaysia under GIPs grant with vot. no. U640.

\section{References}

1. V. Jambulingam, Position Control of DC Motor Using PI Controller, International Journal of Engineering Development and Research, 4(2), 1342-1345, (2016) 
1. P. Maji, B. R. Jammu, S. K. Patra, K. Mahapatra,Design and Implementation of Online Fuzzy Logic Controller on FPGA, Annual IEEE India Conference (INDICON), (2014)

2. G. Jayapalan, G. Agnihotri, .D. M. Deshpande, Real Time Implementation of Incremental Fuzzy Logic Controller for Gas Pipeline Corrosion Control, Advances in Fuzzy Systems, 2014, 1-9, (2014)

3. M. Aamir, On replacing PID controller with ANN controller for DC motor position control, International Journal of Research Studies in Computing, 2(1), 21-29, (2013)

4. D. Hanafi, M. A. Sidik, M. Zoni, Hidayat, Time Base Firing Pulse Delay Control for Improving Single Phase Induction Motor Speed Performance Using Fuzzy Logic Control, ARPN Journal Engineering and Applied Sciences, 11(12), 7515-7521, (2016)

5. N. S. Nise, Control System Engineering,(7nd. ed. Addison-Wesley Publishing Company, Canada, 2014)

6. Zeltom LLC. RAPCON: Real-time Rapid Control Prototyping Platform for Matlab/Simulink, (2013) 